Hunterian Museum, London. For valuable help in the preparation of these I am indebted to Major C. V. IacKay, R.A.M.C,

RFFERrNCEs.
$1 \mathrm{R}$. IV. Lovett: The Treaunent of Infantile Paralysis: Preliminary Report isased on a Study of Vermont Epidemic, 1914. Juurn. Amer. the inscular Factor in Infantile Paralysis. Australian Mell. Joirn. June, 1911 .

2w. C. Machenzie: Evidemie Polionyelitis: Some Biological Studies. Australian Met. Journ... lanuary, 1913.

3 Die Behandlun's der frischen Kinderlitbinung durch Ruhigstellun von Dr. E. Hayer. Deut. med. Woch., June 15th, 1911. Also Inter-
gational Clinics, vol, $\mathrm{i}, 1912$.

\section{THE MODERN TREATMENT OF DIABETES MELLITLS.}

AN ABstract OF THREE Lecteres DELIVERED AT THE LONDON HOSPITAL.*

BY

O. LEITON, M.D., D.Sc., F.R.C.P., PHYSICIAN TO THE HOSPITAL.

A FEW weeks ago the following dialogue might have been heard in the staff room of the London Hospital:

Surgical Colleague: I see that rou are lecturing on the moder treatment of diabetes; now, tell me, are vou going to tell us anythiug which I was not taicht as a student?

Leyton: I believe so.

S. C.: Is there some new drug which possesses a specific action?

L.: Not that I know of

S. C.: 'Then tell me in a nutshell the difference between the modern treatment and that which I was taught.

L.: You were taught that so long as a diabetic was placed on a diet which was free from carbohydrate all was being done that could be done. The main idea in the modern treatment is that a period of alimentary rest leads to an alteration in the metabolism of the diabetic which makes it approach that of the normal indivilual. A patient suffering from serere diabetes is unable to metabolize the carbolyvdrate part of the protein molecule; after alimentary rest, he is able not only to protein the protein but also to oxidize corlohylrote only to utilize all the protein bit also to oxidize carbohydrate given in the food as such. This tolerance for carbohydrate is developed. Limits for protein and fat are found, and these forms of food are not given in unlimited quantities

S. C.: Does the new treatment really allow you to prolong the Jives of young individuals who have developed severe diabetes? I. : Undoubtetlly.

It is this treatment which I wish to describe in sufficient detail to permit all to test the accuracy of my replies in the conversation.

Diabetes mellitus is the name giren to a series of diseases which may be recognized by a departure from the normal metabolism. The change which makes itself most evident is the excretion of dextrose in the urine in quantities which may be detected by the ordinary tests whilst a normal diet is being taken. It is true that sugar appears in the urine in menungitis, exophthalmic goitre, and in gross diseases of the pancreas; these do not come under the heading of diabetes mellitus.

The definition given above inclucles so.called "dietetic ylycosuria." Without wasting time in an academic dis. cussion as to whether such a disease exists, let us assume that it is safer to consider all cases of glycosuria to be diabetes mellitus and treat them as such. No harm will be tone and many lives will be prolonged:

The causes of diabetes mellitus are not known. Perliaps it will assist us to understand the modern treatment if we adopt a speculative explanation of its cause, even if this subsequently be prored incorrect. Diabetes mellitus includes at least three conditions :

1. Sugar in the urine with an increase in the sugar in the blood.

2. No sugar in the mine (at times) with a consiclerable increase of sugar in the blood.

3. Sugar in the urine without any increase of sugar in the blood.

'The two conditions first named are in my opinion due to an altered nerve control of the pancreas, whilst the third is due to the production of a phloretin-like body in some of the tissues.

The similarity between liabetcs mellitus and exoph. thalmic goitre leads me to think that an altered nerve

* The lectures will appear in detail in the Clinical Journal, March, April and lay. control plays an important part. Cannon has shown that if the central end of the phrenic nerve be sutured to the peripheral part of the cervical sympathetic, the nerve grows down, and then the impulses which would have been transmitted to the diaphragm at every respiration are conducted to the thyroid gland, with the result that the animal develops all the signs and symptoms of exophthalmic goitre.

Partial excision of the pancreas produces an effect in an animal simulating in many ways diabetes mellitus. Nevertheless, from post-mortem exaninations, we knoiv that in the majority of diabetics no recognizable lesions are found in the pancreas.

There are many other possibilities. In normal health there is a balance between all the tissues in the body; any departure from this balance is compensated rapidly. Emotions cause a temporary alteration in the balance. Anger and fright stimulate the suprarenal glands, causing the sugar in the blood to be increased, the blood to coagulate more rapidly, the bronchioles to dilate, the muscles to become fatigued less easily, digestion to be inhibited, and the blood to be redistributed in the body. Cannon explains these changes as those which would assist an animal to fight successfully, and that these emotions were originally associated with struggle. Indirectly the same emotions increase the rate of metabolism through the increase in activity of the thyroid. Emotions have a direct effect upon glycosuria too.

Allen found that small highly bred dogs, if a part of the pancreas were removed, and the animals put upon a diet which under ordinary conditions allorved them to be free from glycosuria. passed sugar in the urine when frightened.

This observation upon aninals, and many similar upon man, suggested the possibility that hypnotism might prove of assistance in the treatment of severe diabetes. Our observations on this matter are insufficient to allow me to make any announcement to-day.

\section{Selection of Cases for Treatuent by "Alminentary REsT."}

If it be thought advisable to give a treatment a descriptive name rather than that of its inventor I suggest that the Allen treatment be called the "Treatment by Ali. mentary Rest," for three reasons: (1) It seems to me probable that the alteration in metabolism which occur's when food is withheld is due to rest of the various glands which are stimulated during digestion, and not to the simple absence of food. (2) To prevent confusion between the Allen treatment and the Guelpa treatment, which has been called "the starvation treatment" for quite a long time. (3) Starvation treatment is a name which does not commend itself to patients.

Since the treatnent entails alimentary rest for several days it is obvious that not every case should be submitted to it.

\section{Wethod of Determining Suitability of Case,} (a) Physical.

If the paticnt be suffering from any other disease which is likely to lead to dissolution during the next feiv months he should not be asked to undergo the discomfort of alimentary rest because the recompense for the self-denial is too small.

My experience has taught me that, in spite of the fact that not infrequently a patient suffering from rapidly progressive pulmonary tuberculosis may lose the sugar in the urine as the disease progresses, nevertheless cases of diabetes complicated by pulmonary tuberculosis are not suitable for treatment by the Allen method.

Every effort must be made to be certain that the patient is not suffering from active tuberculosis. We all know that of ten it is extremely difficult to make up our minds on the diagnosis oven when uncomplicated; when diabetes is present the difficulty is increased ten times. Many of the more delicate tests prove fallacious.

The rise of temperature with exercise will not necessarily talie place in a diabetic. 'Tuberculin may not be used because any man who awakens quiescent tuberculosis in a diabetic is guilty of manslanghter.

The examination is limited to inspection, palpation, percussion, auscultation, and radiography. Even the most careful and experienced may err when limited to these 
methods of examination. When examination of the sputum proves the presence of acid-fast bacilli nothing more need be said.

Other forms of infection must be sought for and dealt with as far as possible before treatment is begun.

Especial attention should be paid to the gums; pyorrhoea alveolaris is extremely common in diabetics, possibly because they have a poor resistance to most infections. In screral cases removal of infected teeth and treatment of the gums without any modification in diet has led to the disappearance of even high percentages of sugar from the urine.

It is wise to remember that very severe cases of . very long standing require a slight modification of the routine treatment.

\section{(b) Mental.}

Patients of no education who have not been taught control are unsuitable. 'They prove' a trial to their' physician and do not keep to the diet after they have left the institution in which they have been treated.

A short time ago a young Irish soldier, who had escaped school in the past, was admitted to one of my wards I attempted to explain to him in simple language that he was suffering from a disease which would liill him very soon if he did not consent to undergo certain treatment That, unfortunately, the treatment was one which would not allow him to have very ninch food for some time, and that his rations of potatoes would have to be small for several months. After listening patiently, he said, "Ma fayther never did belave in doctors." The pooi man left the lospital and died a short time later.

The physician. must use judgement and remember always that a patient who begins the Allen treatment and does not continue it is worse off than if he never attempted it.

The method of persuading the patient to undergo the treatment must depend upon the temperament of the patient. The doctor who has seen many cases which have been pronounced hopeless, become free from sugar and return to their normal work will feel justified in painting the future upon the old treatment in its true colours. Perhaps any one with but little experience may not feel justified in doing this, because he is afraid of frightening his patient.

When a patient las consented to undergo the treatment he will ask, "How long shall I have to go without food?" An answer to this question is not easy. It is quite certain that the length of the period does not depend upon the percentage of sugar in the urine.

I am under the impression that the greater the per. centage of sugar in the blood the longer the fast required; in all probability future experience will show that this has many exceptions. Some months ago two cases were admitted to the same ward upon the same day - a girl of 16 passing 12.3 per cent. sugar in the urine, and a woman, aged 35 , passing 1.25 per cent. sugar. The blood of the young girl contained 0.15 per cent. sugar, whilst that of the woman contained 0.5 per cent. sugar. The girl's urine was free from sugar after alimentary rest for forty hours, whilst the woman had to fast six days before the glycosuria disappeared.

\section{Method of Treatment.}

If the patient has developed diabetes comparatively recently a diet poor in fats is ordered for two days pre ceding the period of alimentary rest. This may consist of the same diet as the patient has been accustomed to with the exclusion of butter and fat meat.

Usually I order a breakfast of weak tea with very little milk, two eggs with a small piece of bread; lunch of 100 grams of lean meat, 200 grams of cooked cabbage, 60 grams of boiled potatoes, and a small baked custard pudding. Dinner, a plateful of clear soup, 120 grams of fish, other than salmon, herring, or mackerel, 120 grams of cooked green regetable, an egg and an orange. In exceptional cases of very long standing and severe acidosis, it is wiser to diminish gradually the protein and carbohydrate after removing the fat before submitting the patient to alimentary rest.

Let me warn you against giving a favourable prognosis to patients. who come with a history that for years they have passed sugar in the urine and carried on their work in comfort until a few weeks ago, when they began to be tired and to lose weight and become rather more thirsty than in the past. This sudden alteration often indicates the awakening of tuberculosis; tuberculosis in diabetics may take months to show signs.

During the period of alimentary rest the patient receives a Seidlitz powder every morning, and if that does not prove sufficient it is supplemented by castor oil or an enema. He is kept in bed, but allowed to leave it for the morning bath and for calls of nature. It has been asserted that the sugar disappears more rapidly from the urine when the patient is allowed to talse exercise; this assertion is not easily proved, and even if it were established beyond doubt, one would have to weigh the relative advantages of shortening the period of alimentary rest and the complete control orer the patient. In my opinion complete control is the more important.

The patient should be shielded from all worries and annoyances. Diabetics are short-tempered, and therefore every device must be adopted to meet their wishes whilst under treatment.

During the period of alimentary rest the patient is allowed at brealkfast time 200 c.cm. of weak coffee without milk or sugar, and $100 \mathrm{c.cm}$. of cleai. broth made with an eggspoonful of a meat extract which is poor in protein. At lunch he receires the same as for brealsfast. At tea, $200 \mathrm{c.cm}$. of weak tea. At dinner, $200 \mathrm{c.cm}$. of weak tea and $100 \mathrm{c.cm}$. of clear broth. As much water and soda water as desired is permitted. If the patient is accus. tomed to alcohol, he is allowed the usual amount unless it is really excessive. If not accustomed to any, then alcohol should be given only in cases of severe acidosis or extreme emaciation.

I advise you most strongly to note down every detail, even as to the method of preparing tea and coffee, other. wise you will find your patients being given solutions of sugar, burnt and unburnt, instead of coffee.

The twenty-four-hour specimen starting from 8 in the morning is tested for sugar at 8.30 every morning with Benedict's solution,* or with the indigo test; when it is found free from sugar, we conclude that the metabolism of the patient has altered, and the following progressive diet is begun:

The first day after the urine is free from sugar the dict should contain 5 grams of carbohydrate; this might be given as a quarter of an ounce of white bread, but that would not be satisfying, nor would it tend to alleviate constipation. A vegetable containing a considerable quantity of cellulose and little carbolydrate is chosen in order. that the pangs of hunger may be assuaged by the bulk of the meal, and at the same time the intestine stimulated by the residue of the food.

When in season French beans are the most convenient, because they contain less than 2 per cent. carbohydrate, and 250 grams would be allowed on the first day. When French beans are not obtainable, cabbage boiled in three waters and then stewed in a little clear broth may be used as a substitute; or, if the patient is unable to eat cabbage, 230 grams of cooked spinach, or 200 grams of raw lettuce, or 140 grams of celery may be substituted.

The urine is examined every morning, and, if free from sugar, the diet for the day is given.

Diet For ESTIMATING TOLERANCE. $\dagger$

First Day.-Breakfast: Weak coffee $200 \mathrm{c.cm}$., cooked French beans 75 grams. Lunch: Weak coffee 200 c.cm.; French bean 100 grams. Tea: Weak tea 200 c.cm. Dinner: Weak tea 200 c.cm., French beans 75 grams.

Second Day.-The quantity of vegetable is doubled, and three eggs are added to the diet.

Third Day.-200 grams of lettuce replace 200 grams of French beans, and another 200 grams of French beans are replaced by an equal quantity of boiled cucumber.

Fourth Day.-200 grams of cabbage boiled in one water Firth 200 gr. -200 grams of

Fifth Day.- 30 grams of lean meat are added to the diet alons Fifth Day. -30 grams of lean

with $200 \mathrm{c.cm}$. of clear broth. cream 10 c.cm., one egg, and raw lettuce 200 grams. Lunch Lean meat 100 grams, cooked French beans 200 grams, boiled potato 40 grams. Tea: Weak tea $300 \mathrm{c.cm}$., thin cream $10 \mathrm{c.cm}$. one egg. Dinner: One egg, cooked cabbage 100 grams.

* Copper sulphate 18 grams, sodium citrate 180 grams, sodium carbonate crystals 200 grams, water $1,000 \mathrm{c.cm}$. Boil $5 \mathrm{c.cm}$. with 5 drop of urine for two minutes and allow to cool; if solution remains clear, the daily

作 23, Bartholomew Close, London, E.C. 
Seventh Day. -A fast day.

Eighth Day:- 30 grams of cooked fat bacon replace 30 grams of lean meat.

Ninth Day.-30 grams cooked fat bacon replace 15 grams of lean meat, 15 grams of boiled potato added.

Tenth Day.-30 grams of fat added.

Elcventh Day.-Breakfast: Weak coffee 300 c.cm., thin cream $15 \mathrm{c} . \mathrm{cm}$., one egg, cooked fat bacon 30 grams, raw lettuce 200 grams. Lunch: Cooked lean meat 20 grams, fat 15 grams cooked French beans or their equivalent 120 grams, boiled potato 60 grams, butter 15 grams. Tea : Weak tea 300 c.cm. crean 15 c.cm., boiled potato 30 grams, butter 15 grams. cream 15 c.cm., boiled potato 30 grams, butter 15 grams. 100 grams, cooked French beans 100 grams, butter 30 grams.

Trelfth Day.-Add fat 30 grams.

Thirteenth Day.-Add white bread 15 grams, subtract raw lettuce 120 grams. Add white bread 15 grams at tea, and subtract 30 grams of potato at lunch. Add butter 15 grams. Fourteenth Day. - A fast day.

Fifteenth Day.-Breakfast: Coffee 300 c.cm., cream 20 c.cm. ne egg, cooked fat bacon 30 grams, raw lettuce 100 grams, white bread 15 grams, butter 15 grams. Lunch : Cooked lean meat 60 grams, fat 30 grams, cooked French beans 120 grams, boiled potato 30 grams, butter 60 grams. Tea: Tea 300 grams white bread 15 grams, one egg, butter 30 grams. Dinner. Clea broth 200 c.cm., one egg, cooked cabbage 120 grams, boiled potato 30 grams, butter 60 grams.

The diet on the fifteenth day represents carbohydrate 42 grams, protein 54 grams, fat 192 grams. Note that the carbohydrate is fairly well divided: Breakfast 12 grams, lunch 8 grams, tea 9 grams, dinner 13 grams.' The energy provided by the diet is calories 2,112, sufficient for an average man who is not doing any manual work. If sugar remains absent the diet is altered by the addition of $\dot{3}$ grams of carbohydrate daily with a diminution of 6 giams of fat.

Every seventh day should be a fast day or a half-ration day; in the milder cases half-ration days suffice.

Under no conditions be influenced by the old-fashioned idea and add to the protein in the diet; if you do, quite frequently sugar will return, and you may think that it is due to the increase in carbohydrate and viminish it in eiror. This means that no so-called antidiabetic bread or biscuits may be given.

When we wish to reduce the weight of obese patients we give them an excess of protein ; this applies to diabetics too, an excess of protein causes them to lose weight. Many years ago I found that by substituting cellulose, which is not absorbed, for protein patients stopped losing weight.

There is nothing gained by giving oatmeal instead of bread; as long as the carbohydrate is starch and not sugar its absorption is fairly slow; the type of starch makes no difference.

Various diets suggested during the last few months have the same underlying idea, although the authors of the diets frequently do not seem to recognise it-namely, the diminution in the quantity of protein.

The problem arises, What should be done when the sugar returns? The patient should fast until the sugar disappears; as a rule twenty-four hours suffice. Then one of two methods may be adopted : the progressive diet may be followed, but at double the previous rate, until the carbohydrate reaches two-thirds of that at which sugar returned, and then fat is added until the necessary amount of energy is being taken. Or the diet is halved, then the protein is rapidly increased up to the amount it was when sugar appeared and the fat increased at the same time. The carbohydrate is gradually increased until it reaches twothirds of the amount that led to the return of sugar.

We must realize that protein and fat in excess will both lead to the reappearance of sugar in the urine.

The reappearance of sugar after some time without any alteration in the diet does not necessarily mean that a fresh period of alimentary rest need be prescribed, or even that a modification in the diet is essential. Some emotional disturbance may have led to glycosuria. Amongst my patients is a woman who has a return of glycosuria whenever the interval between letters from her son, who is fighting in France, is more than five days. Mental perturbation does not always lead to the same result. A severe case of diabetes, whose carbohydrate limit rose to 60 grams of carboliydrate, had bombs dropped in his garden on two occasions, he lost his brother, sister, and wife all within three months, but he did not have a return of sugar.

Exposure to cold, anxiety about catching a train, and many other minor things may lead to the return of sugar, and should be inquired about before ariy alteration in diet is ordered.

In olden days much attention was paid to the weight of the patient, and the unwarrantable assamption was made that so long as the weight was maintained all was well with the patient. Try and make your patients believe the truth, that the weight is of comparative unimportance, that no diabetic has ever faded away. Make them ex. change an interest in weight for one in the result of the test of the urine with Benedict's solution.

As a rule the gain in weight when the patient is upon the optimum diet is very slow, perhaps a few ounces a week. In the majority of cases a rapid increase means that oedema is developing. An exception came my way a short time ago in a man who had gamed $17 \mathrm{lb}$. in six weeks. For two years he had been upon the old.fashioned treatment, and had become a skeleton; and a weak skeleton at that. The death of his medical adviser had led to his adopting the Allen treatment. He emphasized the rarity of the rapid increase in weight with completely beneficial results by making a somewhat uuusual remark: "My doctor died; if he had not, I should."

In the past diabetics were not allowed to take much exercise, because it was thought that exercise would lead to loss of weight. It is found that a moderate amount of exercise allows the patient to metabolize more carbo. hydrate, and exercise is now ordered; the anount taken should be the same every day, otherwise it must be remembered that upon those days when less exercise is taken less carbohydrate must be included in the food.

The results obtained are better than those by any method adopted to date. You must remember that the treatment is not a cure, but that when carried out in the best possible manner a diet is found which allows the patient to live indefinitely, and to lead a useful life. Perhaps a cure will be discovered during the next few years which will allow us to permit the patients whom we have kept alive to return to a normal diet.

The treatment has not been in use long enough for us to have decided whether the carbohydrate tclerance gradually increases. In some cases $I$ believe there are indications of this.

Young people who have developed the condition com. paratively recently derive the most benefit from the treat. ment.

of the seventy cases of severe disease which have come under my observation four have died from tuberculosis. These led me to exclude those who showed signs of that condition. I hope shortly to record what I believe to be the most satisfactory treatment when tuberculosis is present.

One patient died from pneumonia, two from gangrene which had started some time before they came under treat. ment. Four patients died within a day or two of admission to the hospital.

The majority are enjoying good health, and many are asking why they were not put upon the treatment a long time ago.

\section{CARDIAC DISEASE IN SOLDIERS ANB RECRUITS.}

\section{By Captain W. SCARISBRICK, R.A.M.C.(T.).}

THIs article has been written with the purpose of com. paring the incidence of heart disease amongst soldiers and recruits, and embodies my personal notes. The great majority of the soldier cases had been on active service abroad, and included all degrees of severity of heart disease; the recruit cases also formed a fair representation of the different types of cardiac affection.

Notes of 218 cases of heart disease occurring amongst soldiers and 151 found amongst recruits have been collected; they have been classified into five broad and fairly distinct groups. These groups were selected because, whilst being sufficiently comprehensive, it was considered that classification in this manner should not prove toc difficult, and the choice of treatment and the prognosis as to future utility would be moderately easy.

A few words of explanation as to the reason for assign. ing individual cases to a particular group may be useful. In the main, clinical and general signs, symptoms, and 